\title{
Interlocuções teóricas entre Paulo Freire e Ernst Bloch: diálogos acerca do Princípio e da Pedagogia da Esperança ${ }^{1}$
}

\author{
Caroline Terra de Oliveira \\ Programa de Pós-Graduação em Educação Ambiental da Universidade Federal do Rio Grande-RS - Brasil \\ caroline.tutoria@gmail.com \\ Victor Hugo Guimarães Rodrigues \\ Instituto de Educação da Universidade Federal do Rio Grande - RS - Brasil \\ filosofoonirico@yahoo.com.br
}

EDUCAÇÃO: Teoria e Prática, Rio Claro, SP, Brasil - elSSN: 1981-8106

Está licenciada sob Licença Creative Common

\section{Resumo}

Neste artigo propomos discutir a concepção de esperança e sonho diurno a partir dos escritos de Ernst Bloch e Paulo Freire. Tomando como base a produção de Ernst Bloch, exploramos a filosofia da esperança, como sendo a expressão de um afeto expectante positivo, a partir do imperativo de a compreendermos como ato relacionado a um compromisso político de busca pela constituição das utopias concretas. A problematização do termo a partir de Paulo Freire, por sua vez, insere a discussão acerca da importância da Pedagogia da Esperança como processo de aprendizagem política de exercício e comprometimento com uma utopia. Neste debate, resgatamos o conceito de esperança, inédito viável e inacabamento em Freire. Assim, reivindica-se a necessidade de uma reflexão crítica sobre a importância desse tema na atualidade frente aos discursos fatalistas neoliberais, bem como o imperativo de nos orientarmos, no sentido de construirmos sujeitos de sonhos que desafiem o instituído e que vejam significado na luta por uma pedagogia da esperança que alcance tanto a escola quanto os demais espaços educativos de formação do ser humano.

Palavras-chave: Pedagogia. Esperança. Sonho diurno.

\section{Theoretical dialogues between Paulo Freire and Ernst Bloch: dialogues about the Principle and Pedagogy of Hope}

\begin{abstract}
In this article we propose to discuss the concept of hope and daydream from the writings of Ernst Bloch and Paulo Freire. Based on the production of Ernst Bloch explored the philosophy of hope, as an expression of affection expectant positive, from the imperative to

\footnotetext{
${ }^{1}$ Trabalho apresentado em forma de comunicação no XIV Fórum de Estudos Leituras de Paulo Freire. Erechim: UFFS, 2012
} 
understand how the act related to a political commitment by the constitution from seeking concrete utopias. The problematization of the term from Paulo Freire, in turn, enters the discussion about the importance of Pedagogy of Hope as a political learning process and committed to a utopia. In this debate, we rescued the concept of hope, unpublished and unfinished viable in Freire. Therefore, it is claimed the need for a critical reflection about the importance of this subject today in the face of neoliberal discourses fatalists, and the imperative to orient ourselves with the objective of building dreams subjects that challenge the established and they see meaning in the struggle for a pedagogy of hope that both reach the school, as other educational spaces training of human beings.

Keywords: Pedagogy. Hope. Dream day.

\section{Interlocuciones teóricas entre Paulo Freire y Ernst Bloch: diálogos acerca del Principio y de la Pedagogía de la Esperanza}

\section{Resumen}

En este artículo proponemos discutir la concepción de esperanza y sueño diurno a partir de los escritos de Ernst Bloch y Paulo Freire. Tomando como base la producción de Ernst Bloch, explotamos la filosofía de la esperanza, como siendo la expresión de un afecto expectante positivo, a partir del imperativo de que la comprendamos como acto relacionado a un compromiso político de búsqueda por la constitución de las utopías concretas. La problematización del término a partir de Paulo Freire, a su vez, insiere la discusión acerca de la importancia de la Pedagogía de la Esperanza como proceso de aprendizaje político de ejercicio y comprometimiento con una utopía. En este debate, rescatamos el concepto de esperanza, inédito, viable e inacabamiento en Freire. Además, se reivindica la necesidad de una reflexión crítica sobre la importancia de este tema en la actualidad frente a los discursos fatalistas y neoliberales, así como el imperativo de orientarnos, en el sentido de construir sujetos de sueños que desafíen lo instituido y que vean significado en la lucha por una pedagogía de la esperanza que alcance tanto la escuela como los demás espacios educativos de formación del ser humano.

Palabras clave: Pedagogía. Esperanza. Sueño diurno.

\section{Considerações iniciais}

A palavra utopia foi utilizada, pela primeira vez, em 1516, pelo escritor Thomas More em sua obra intitulada "De optimo statu reipublicae deque nova insula Utopia", traduzida como Sobre o melhor estado de uma república e sobre a nova ilha de Utopia. Sendo a sua obra literária mais divulgada, aborda a crítica à sociedade inglesa daquele período: condena a vida de riquezas da nobreza e do clero, a política de expulsão dos camponeses de suas terras e a consequente concentração da propriedade fundiária, contrastando com o contexto de miséria e exploração da massa de trabalhadores. O livro apresenta uma 
sociedade imaginária, organizada de acordo com a propriedade comum dos bens, uma comunidade com ausência de conflito de interesses, que promove a justiça e a igualdade social.

O significado do termo Utopia, tal como empregado por Thomas More, incorporou-se ao sentido universal do senso comum, referindo-se a todo projeto de sociedade impossível de ser materializado, irrealizável, que somente está restrito ao plano do imaginário. Entretanto, esse sentido comum do termo revela-se como limitado, uma vez que consiste em apenas uma das possibilidades de se pensar o fenômeno utópico. Sendo assim, amplioue o significado do conceito de utopia quando empregado pelos filósofos Ernst Bloch (2006, 2005) e Gaston Bachelard (1985, 1988, 1996).

Ernst Bloch concedeu especial atenção à utopia em diversas de suas obras, sendo a sua principal O Princípio Esperança, de 1950. Na sua concepção, a utopia se expressa como força de transformação, alicerce da esperança crítica, apresenta-se como dimensão ontológica do ser humano. Está presente na história da humanidade, na concretização das utopias sociais, econômicas e religiosas, manifesta-se na pintura, na poesia, na música, no teatro e na arquitetura.

O significado do termo utopia concreta, presente na concepção de Bloch, assemelha-se ao sentido da utopia crítica do educador Paulo Freire (1979; 1981; 1983; 1986; 1987; 2000; 2006). Destaca-se que a concepção de sonho em Freire está intimamente relacionada à necessária busca de um conhecimento crítico sobre a realidade e mobilização de práticas transformadoras das condições opressoras de nossa sociedade.

Sendo assim, busca-se, à luz dos autores citados, refletir o sentido da utopia como uma das urgências nos dias atuais, e a obra de Freire, em especial, mostra-se de grande relevância à medida que traz reflexões de um educador que vivenciou a realidade de exploração na América Latina. Desse modo, ressalta-se a importância da sua vivência enquanto educador popular comprometido com uma pedagogia utópico-libertadora.

Os temas discutidos por esses autores expressam a importância de nos orientarmos no sentido de mantermos nossa esperança, de construirmos sujeitos de sonhos que desafiam o instituído e que vejam significado na luta pela construção dos projetos considerados irrealizáveis. Instigam-nos a pensar sobre os desafios que valem a pena ser enfrentados no caminhar da busca pelos sonhos possíveis. Salienta-se a questão da importância da 
manutenção da utopia como uma das urgências do nosso período, caracterizado pela carência de sonhos de um mundo mais humano, mais justo e fraterno.

A intenção não é repeti-los, mas compreendê-los e recriá-los, buscando uma reflexão crítica de suas teorias. A partir dessa problematização, procura-se enfatizar a potencialidade dos sonhos diurnos ou sonhos possíveis, como destaca Paulo Freire, na construção de sujeitos utópicos e de práticas educativas que atuem a partir da perspectiva de que "mudar é difícil, mas é possível" (FREIRE, 2000, p.114).

\section{Paulo Freire e Ernst Bloch: diálogos acerca do Princípio e da Pedagogia da Esperança}

Freire assume a esperança como sendo um conceito central à condição humana de ser mais, afirmando-se como necessidade ontológica. Especialmente, referindo-se à prática dos educadores, Freire inter-relaciona a concepção de esperança aos conceitos de inéditoviável, utopia e sonho possível. Em sua obra Ação cultural para a liberdade (1981), o autor remonta à esperança como desafio à ação de todo educador que compreende a educação como campo de possibilidades de anúncio e concretização dos sonhos possíveis. Nesse sentido, o educador que assume a esperança como ato pedagógico, propõe uma prática orientada pelo compromisso e ousadia de contestar as propostas educativas que vão ao encontro dos ideais da estrutura dominante de distribuição do capital.

Freitas (2004, p.82, grifo do autor) afirma que a esperança é um tema recorrente nas últimas obras de Freire, constituindo-se "enquanto pedagogia que orienta a construção do sonho coletivo a partir da vivência da dialeticidade da denúncia e do anúncio, viabilizando a construção do inédito-viável e desafiando o senso comum a orientar-se a partir de uma consciência democrática".

Sobre esse aspecto, com base em Paulo Freire, Ghiggi (2001, p. 471, grifo do autor) coloca a esperança como componente importante na criação de “(...) centros de referência $e$ formação: para reflexão, socialização de experiências, discussão e construção de alternativas de falas, teorizações provisórias em torno de práticas de vida e redes de solidariedade que possam dar suporte aos avanços em direção à utopia". Ainda assim, o autor afirma que a linguagem crítica e a esperança se constituem como condições necessárias à tarefa da 
autoridade docente, conquanto seja compreendida como "caminho que possibilita a conceituação sistemática do mundo querido pelos envolvidos; é o que possibilita analisar condições sociais e materiais onde sonhos, alegrias, esperanças e desejos são gerados" (GHIGGI,2001, p. 475, grifo do autor).

Desse modo, a potencialidade transformadora da ação com esperança exige a assunção de uma pedagogia para além da espera vã; nesse sentido, requer a necessidade de romper com as concepções fatalistas da realidade e superar o estado de acomodação, resignação e conformismo: "Na verdade, quem espera na pura espera vive um tempo de espera vã. A espera só tem sentido quando, cheios de esperança, lutamos para concretizar o futuro anunciado de que vai nascendo da denúncia militante" (FREIRE, 1981, p.48). Destaca-se que o autor concebe a Pedagogia da Esperança como processo que emerge da indissociabilidade entre denúncia e anúncio: "Não há anúncio sem denúncia, assim como toda denúncia gera anúncio. Sem este, a esperança é impossível” (FREIRE, 1981, p. 48).

Assim como Freire, Ernst Bloch (2005, p.148) associa a dimensão da esperança à esfera da criticidade, na compreensão da história como possibilidade, desafiando o senso comum e a concepção ingênua e fatalista da realidade. "A questão que se coloca é saber se em que medida o contragolpe antecipador não se confunde com um contragolpe que simplesmente embeleza o existente".

Em Freire, a prática pedagógica voltada à esperança crítica é processo de construção de conhecimento acerca da realidade denunciada e nisto se insere a função utópica da educação. Assim, vivenciar a história como campo aberto de concretizações é considerar que a educação se constitui como contexto de possibilidades, o que engendra o significado do conceito de esperança crítica ou verdadeira, como denomina Freire (1981, p. 48): “Não pode haver esperança verdadeira, também, naqueles que tentam fazer do futuro a pura repetição de seu presente, nem naqueles que veem o futuro como algo predeterminado. Têm ambos uma "noção" domesticada da História".

É imperativo enfatizar que, ambos os autores, destacam a necessidade de educarmos a nossa esperança, no sentido de ultrapassar o aspecto da fuga e da resignação que coloca o ser em conformidade com a precariedade da sua situação existencial. Nesse aspecto, educarmos a nossa esperança significa extrairmos do nosso sonho diurno a compreensão das nossas necessidades e anseios e o direcionamento das nossas ações. Para além da 
tendência contemplativa, a esperança deve resultar em práxis: "Não no sentido do entendimento meramente contemplativo, que aceita as coisas como são e estão no momento, mas sim no da participação, que as aceita em seu movimento, portanto, também como podem ir melhor" (BLOCH, 2005, p. 14).

A esperança se contrapõe à agonia, a qual, de acordo com Bloch (2005), é tornada na sociedade atual, especialmente na Ocidental, como fundamento ontológico do ser humano. Nesse caso, a desesperança, como aporte da agonia e do desespero, apresenta-se como indicativo insuportável para as necessidades humanas. Assim sendo, enfatizamos a necessidade das nossas ações estarem mediadas pela "esperança lisonjeira e perversamente estimulada" (BLOCH, 2005, p. 14), pois, do contrário, o medo e o niilismo passam a sustentar uma existência desesperadora e um temor em relação ao vazio que compreende o futuro.

No campo das possibilidades do que ainda-não-se-tornou ou do que pode-vir-a-ser, a esperança manifesta a incompletude do ser humano, do novo possível: "Somente ao se abandonar o conceito fechado e imóvel do ser surge a real dimensão da esperança". (BLOCH, 2005, p.28). Ela necessita da práxis para transpor o mero entusiasmo, a contemplação, assim, precisa estar mediada pelo movimento da materialidade objetiva. Desse modo, o saber como teoria-práxis se diferencia do saber contemplativo, pois está situado para além da ilusão de uma vida melhor, tornando-se ação intencional, projetada e planejada. O fenômeno do ter esperança, portanto, na concepção da teoria crítica, é compreendido não somente como fundamento ontológico, mas como categoria da possibilidade, a qual se desenvolve enquanto práxis, no movimento de conquista de algo para si.

Quando nos remetemos à categoria sonho em Freire (1979; 1981; 1983; 1986; 1987; 2000; 2006), não podemos deixar de refletir acerca da expressão inédito viável, intrinsecamente relacionada à concepção libertadora de educação. O inédito viável é expressão das alternativas e projetos voltados para o campo das possibilidades, constrói-se a partir da práxis humana. Constitui desafio, compromisso histórico, sonho coletivo e possibilidade de transformação. Expressa sonhos, valores e aspirações.

Dessa forma, o sentido do conceito de utopia na obra de Freire ultrapassa o significado relacionado ao senso comum: não constitui projeto irrealizável, mas, sim, processo transformador e mobilizador, que envolve a relação dialética entre conhecimento crítico e 
práxis social.

A utopia exige o conhecimento crítico. É um ato de conhecimento. Eu não posso denunciar a estrutura desumanizante se não a penetro para conhecê-la. Não posso anunciar se não conheço, mas entre o momento do anúncio e a realização do mesmo existe algo que deve ser destacado: é que o anúncio não é anúncio de um ante-projeto, porque é na práxis histórica que o anteprojeto se torna projeto. É atuando que posso transformar meu anteprojeto em projeto [...] (FREIRE, 1979, p. 28).

Salientamos que o caráter antecipatório da esperança está interligado ao horizonte da temporalidade, a qual inclui a expectativa do ainda-não como fator do que ainda não ocorreu ou se concretizou. Contudo, apesar de estar situado para além da realidade que está disponível de modo imediato, possui, na sua intencionalidade, a possibilidade de satisfação e concretização. A esperança tem na base de sua expectativa a autopreservação, o interesse de romper com a situação existencial de angústia, sofrimento e privação ou, como denomina Bloch $(2005 ; 2006)$ com o ruim existente. Entretanto, como alicerce da autopreservação do indivíduo, a esperança necessita do interesse revolucionário para se tornar autoexpansão.

Desse modo, quando limitada ao âmbito da autopreservação, a esperança trabalha com a satisfação do imediato. Entretanto, para ultrapassar este aspecto do imediatismo e se tornar autoexpansão, necessita ser empreendida à luz da desmitificação da realidade, como resultado do processo de esclarecimento das contradições que tornam o humano um ser oprimido. No sentido da autoexpansão, a esperança se constitui como fome economicamente esclarecida (BLOCH, 2005), da qual parte o imperativo de satisfação e realização para aquilo que o impulsiona para frente.

Nessa perspectiva, o processo do planejamento assume uma função principal: o de antecipar, em termos ideais, o direcionamento de nossas ações. $O$ ato de planejar está no cerne da esperança que parte de um propósito, que determina o modo de agir e submete a ação humana à vontade do sujeito que sonha. Nesse contexto, o conhecimento é elemento fundamental para a superação de dificuldades ao sujeito sonhador: "Para remover a dificuldade é necessário não só o conhecimento em termos da escavação daquilo que houve mas também em termos de um planejamento do que haverá. De forma que é necessário o conhecimento, que contribuirá decisivamente para este devir [...]" (BLOCH, 2005, p.131). 
Por esse motivo, o conceito de utopia está relacionado ao sentido de esperança crítica, uma vez que se reivindica a necessidade de construção de um conhecimento crítico que, na medida em que reflete criticamente o passado, possibilite vislumbrar possibilidades e propostas de mudança concreta da realidade opressora, fortalecendo a práxis transformadora.

É antes de tudo o interesse revolucionário, com seu conhecimento de como está ruim o mundo e seu reconhecimento do quanto ele poderia ser bom como um outro mundo, que necessita do sonho desperto da melhoria do mundo: ele o fixa na sua teoria e sua práxis de modo totalmente a-heurístico, totalmente apropriado ao tema (BLOCH, 2005, p.97).

Bloch critica o interesse e empenho da humanidade em relação à construção de um conhecimento que se pretende prático e imediato, fato que causa barreira às teorias e às obras que transcendem o estabelecido no período histórico, considerando-as irrealizáveis. A dificuldade do caminho em direção à realização da obra está relacionada à época histórica em que esta é intencionada, portanto, não constitui barreira que reside no sujeito, pois mesmo que o sonhador possua esforço e vontade de realização, no momento que a ideia transcende o plano ou esboço, iniciam-se os conflitos, as dificuldades e tentativas frustradas. Tal ideia retoma o sentido dos contra-sonhos, enfatizado na Pedagogia da Indignação.

Desse modo, há na história uma barreira socioeconômica diante da visão que não pode ser transposta nem mesmo pelo espírito mais ousado. Muitas antecipações, antevisões vieram à consciência existente e foram destacadas, elucidadas por ela mesma no ainda-nãoconsciente. Contudo, a barreira social obstruiu a execução. (...) Frequentemente, as obras que transcendem a sua época nem mesmo podem ser intencionadas, que dirá realizadas. Isso foi destacado por Marx com a afirmação de que a humanidade sempre se atribui as tarefas que pode cumprir. (BLOCH, 2005, p.129-130).

O ser humano é movido por impulsos, por sentimentos que despertam desejos, os quais incentivam o humano a se orientar para a satisfação do vazio, da carência que encontrou na realidade imediata. Em Freire (1979; 1981; 1983; 1986; 1987; 2000; 2006), por exemplo, a esperança nasce da dialeticidade dos sentimentos de raiva, indignação e amorosidade. A indignação está fundada na revolta diante da miséria, das injustiças, das situações que 
negam ao humano o direito de ser mais.

Os sentimentos de raiva e indignação constituem fatores motivadores de negação e busca de mudança de um contexto indesejável. A procura pela materialização de um sonho, portanto, pode, também, partir desses sentimentos percebidos como negativos ao ser humano.

A esperança existe como a idealização do objetivo e propósito planificados na imaginação criadora, sendo esta necessária à ousadia e direcionamento do olhar, antevendo a concretude do sonho diurno. De acordo com Bloch (2005), os sonhos diurnos, aliados à imaginação criadora de um mundo melhor, reforçam as imagens e a ousadia de romper com a possibilidade de renunciar à esperança:

Mas quantos outros sonhos diurnos ideais conservaram a coragem e a esperança dos seres humanos, não desviando os olhos do real, mas, ao contrário, encarando a sua evolução e o seu horizonte. Quantos reforçaram, pela via da antecipação, do sobrepujamento e de suas imagens, a vontade de não renunciar (BLOCH, 2005, p. 79).

Assim como Freire, Bloch ressalta que a esperança possui em si as potencialidades tanto para a construção de um existente abstrato e idealista, quanto para uma antecipação dialeticamente explosiva e real. Nessa perspectiva, o conceito de esperança em Freire (1979; $1981 ; 1983 ; 1986 ; 1987 ; 2000 ; 2006)$, relaciona-se aos sentidos construídos por Ernst Bloch, uma vez que relaciona o imperativo dessa categoria ao interesse revolucionário de ultrapassar o ruim existente para a concretização dos sonhos com uma vida melhor. É nesse sentido que ambos os autores defendem a argumentação em torno do conceito de esperança crítica, a qual envolve uma incumbência revolucionária, compreendendo uma irreconciliação do sujeito com a sua situação existente.

E se o homem é capaz de perceber-se, enquanto percebe uma realidade que lhe parecia "em si" inexorável, é capaz de objetivá-la, descobrindo sua presença criadora e potencialmente transformadora desta mesma realidade. O fatalismo diante da realidade, característico da percepção distorcida, cede lugar à esperança. Uma esperança crítica que move os homens para a transformação (FREIRE, 1983, p. 51). 
Em Freire, as possibilidades emergem das situações-limite, ou seja, a educação, em suas contradições, nas suas características e mazelas cotidianas inclui as condições para a vivência da esperança e concretização dos sonhos possíveis. Desse modo, o horizonte da possibilidade, a reconstrução de um contexto de realidade parte de um espaço de vivências sufocante e opressivo. Destaca-se que, de um contexto repressor e angustiante, enrijecido pela individualização das relações sociais, parte o imaginário sobre um mundo passível de transformação, compreendendo o horizonte da esperança que impulsiona a busca pela concretização com um além melhor. Portanto, a contradição se constitui na alavanca da práxis, desafia os educadores à vivência e construção cotidiana da Pedagogia da Esperança. É importante destacar que o inédito-viável se constitui como conceito que expressa a nossa crença no sonho, na possibilidade da concretização das utopias e no engajamento e necessidade de estabelecermos uma pedagogia crítica. Tal como registra Ana Freire (2008) ele se nutre da esperança que existe em cada ser humano na busca por um mundo mais justo, solidário e humanizador, tendo em seu fundamento a inconclusão humana. $O$ inédito viável é o sonho socialmente pretendido, é a utopia historicamente possível que renasce permanentemente: "É sempre, pois devenir, pois alcançado o inédito-viável pelo qual sonhamos e lutamos, dele mesmo, já não mais um sonho que seria possível, mas o sonho possível realizando-se, a utopia alcançada, que faz brotar outros tantos inéditos viáveis [...]" (FREIRE, A.M.A., 2008, p.233).

Paulo Freire (1987), em sua obra Pedagogia do Oprimido, cita Álvaro Vieira Pinto, reportando-se à construção do conceito das situações-limites como sendo as condições concretas e históricas de um determinado contexto de realidade que desafiam os homens à sua negação ou aceitação passiva. O sentimento e o enfrentamento em relação às situaçõeslimites não dependem da dimensão do problema, mas da compreensão que os humanos possuem diante das possibilidades de reinventar novas condições de sua existência individual. As situações-limites, portanto, seriam a nascente do qual parte o sentido da existência de um comportamento não contemplativo: "Esta é a razão pela qual não são as situações-limites, em si mesmas, geradoras de um clima de desesperança, mas a percepção que os homens tenham delas num dado momento histórico, como um freio a eles, como algo que eles não podem ultrapassar" (FREIRE, 1987, p.90). 
Partindo desse entendimento, destaca-se que a contradição e a opressão, o enrijecimento das relações sociais, potencializam a busca pela concretização das utopias possíveis. Sendo assim, ressaltamos a importância do aspecto educativo da indignação política, como sentimento necessário para a ousadia do mover-se na esperança frente a contextos opressivos, angustiantes e desesperadores. Nesse aspecto, Freire destaca a diversidade de sentimentos que integram o cotidiano dos educadores e que fundamentam suas práticas pedagógicas, sendo presente a indignação e o medo como processos que podem contribuir para o imobilismo ou desafiá-los ao espanto, a suspeita e à ousadia, enfim, provocá-los ao exercício crítico de usas opções políticas, metodológicas e epistemológicas. Segundo Freire (1986, p.70): “[...] o medo vem de seu sonho político, e negar o medo é negar o sonho". o medo pode corresponder ao respectivo conteúdo que paralisa ou mobiliza o educador a contestar as obviedades teóricas e a romper com a vivência da desesperança: [...] o que não posso permitir é que meu medo seja injustificado e que me imobilize. Se estou seguro do meu sonho político, então uma das condições para continuar a ter esse sonho é não me imobilizar enquanto caminho para a sua realização. E o medo pode ser paralisante." (FREIRE, 1986, p.70).

Outro aspecto fundante da concepção de educação libertadora em Freire diz respeito à construção do diálogo entre educador e educando: este deve se assentar na esperança confiante, na fé e na capacidade humana de ser mais. Em Pedagogia do Oprimido, o autor salienta esse aspecto afirmando que "o diálogo é o encontro dos homens para Ser Mais, não pode fazer-se na desesperança. Se os sujeitos do diálogo nada esperam do seu quefazer, já não pode haver diálogo. O seu encontro é vazio e estéril. É burocrático e fastidioso" (FREIRE, 1987, p.82). O diálogo construído a partir da esperança confiante compreende que o conhecimento é realizado a partir da escuta do outro, ou seja, da leitura de mundo que fundamenta sua história e a especificidade de seus saberes.

Ernst Bloch (2005; 2006) e Paulo Freire (1979; 1981; 1983; 1986; 1987; 2000; 2006) enfatizam que a esperança funda-se na possibilidade de projetarmos utopias, escolhas e desejos, caminhando esperançosamente pela busca da materialização dos nossos anseios. Em Freire, portanto, a imaginação criadora possui relevância na medida em que se mostra como um desenho de um mundo sonhado, como destaca em Pedagogia da Esperança: "[...] o sonho é tão necessário aos sujeitos políticos, transformadores do mundo e não adaptáveis 
a ele, quanto, permita-se-me a repetição, fundamental é, para o trabalhador, que projete em seu cérebro o que vai executar antes mesmo da execução" (FREIRE, 2006, p.92). À esperança, portanto, insere-se a concepção de inacabamento, sendo a compreensão da infinitude de cada sujeito: o outro em seu contexto é o inacabado, é abertura infinita.

\section{Considerações finais}

Os sonhos e a esperança necessitam do imaginário para que o homem, além de recusar a realidade vivida, possibilite recriá-la, reinterpretá-la e conjeturar o campo de possibilidades existentes. A atividade criadora do ser humano é explorada no âmbito da imaginação, sendo assim, todo ato criativo é um ato utópico, ao mesmo tempo em que também se constitui como um ato político, pois as alternativas e obras imaginárias revelam uma intencionalidade. Portanto, a utopia concreta, alicerçada na reflexão crítica e imaginação criadora, não constitui fantasia vaga, vazia de conteúdo e sentido; antes, revela uma determinada maneira de compreender o ser humano, o seu papel na sociedade e as relações que ele estabelece com o outro.

Através da reflexão crítica e consciência de seu indeterminismo, pela constatação de um contexto de realidade imperfeito e indesejado, o ser humano reinterpreta o existente como possibilidade do que ainda não é, mas que pode vir a ser. O ainda-não, nesse sentido, constitui um estado ontológico presente ao sujeito que sonha, fundamento da esperança, baseado no desejo de alcançar o ainda não existente.

Baseamos em Ernst Bloch para afirmar o entendimento da esperança como fundamento ontológico do ser humano e na compreensão do seu conteúdo antecipatório: nesse sentido, a esperança possui um interesse revolucionário, pois possibilita a criação de imagens que se encontram para além da realidade que está disponível de modo imediato, sendo a expressão de uma consciência antecipadora. Sendo assim, tanto o mundo exterior quanto o interior se apresentam como contextos modificáveis, que exprimem a natureza inconclusa do ser humano, a sua disponibilidade para sonhar:

Nenhum sonhar pode ficar parado; isso não faz bem. Porém, quando ele se torna um sonhar para adiante, a sua causa tem bem outro efeito desgastante. É excluído o aspecto esmaecido, debilitador, que pode ser próprio do mero anseio; este mostra, então, do que 
realmente é capaz. Desde o princípio exige-se das pessoas que se adaptem ao tamanho do cobertor e elas aprendem a fazer isso; só que os seus desejos e sonhos não obedecem. Nesse ponto, praticamente todas as pessoas estão insatisfeitas, consideram-se dignas de uma vida melhor [...] (BLOCH, 2006, p. 451).

Ernst Bloch enfatiza que o processo de construção de um algo parte de um aindanão, de uma situação de carência e de necessidade de supressão dessa falta. O ainda-não é expressão do desejo de um possível-real, é o não-ter um algo, é o ponto de partida de um almejar: “(...) a fome torna-se uma força produtiva na linha de frente constantemente em irrupção de um mundo incompleto. Desse modo, o não como ainda-não processual transforma a utopia na condição real da incompletude [..]" (BLOCH, 2005, p.303).

Sendo assim, Bloch e Freire compreendem a utopia enquanto potência que pensa o homem e o seu contexto, a qual deve estar voltada para a crítica da realidade, na medida em que a entende como um processo dinâmico, inacabado e insatisfatório, como algo que não se limita ao imediato.

Freire assume a Pedagogia da Esperança como aprendizagem política de exercício e comprometimento com uma utopia. Nessa perspectiva, em um contexto de desesperança e desespero, encontra-se o imperativo de educarmos a nossa esperança. Nesse debate, destaca a necessidade da confiança e lealdade aos nossos sonhos, no sentido de estar situado para além da pura percepção de nossa inconclusão e limitações, mas significar a utopia a partir da luta política e concreta. O sonho também é colocado como objeto de reflexão filosófica, pois confere à consciência a possibilidade de entendimento sobre a realidade concreta: dessa forma, o sonho porque lutamos também é ato de conhecimento do mundo e da nossa subjetividade, dos nossos anseios e da percepção da viabilidade e concretude dos nossos projetos.

Situamos, portanto, a Pedagogia da Esperança de Paulo Freire como sendo um campo de possibilidades de anúncio e concretização dos sonhos possíveis. Nesse processo, compreende a denúncia como exercício educativo que desafia o senso comum e a concepção ingênua e fatalista da realidade. Destaca-se a natureza política da esperança, com base na ação educativa que está voltada à crítica ao processo neoliberal da educação, à lógica empresarial como orientadora das ações na escola e das políticas educacionais. Com 
base em Paulo Freire, portanto, a Pedagogia Onírica desafia os educadores a constituírem espaços de luta pelas condições sociais que permitam o fortalecimento da perspectiva utópica da educação, fundamentada na vivência de práticas pedagógicas voltadas para a esperança.

\section{Referências}

BACHELARD, G. A poética do espaço. São Paulo: Martins Fontes, 1996.

BACHELARD, G. A poética do devaneio. São Paulo: Martins Fontes, 1988.

BACHELARD, G. O novo espírito científico. Rio de Janeiro: Tempo Brasileiro LTDA, 1985.

BLOCH, E. O princípio esperança. Rio de Janeiro: Contraponto, 2006. 3.v.

BLOCH, E. O Princípio Esperança. Rio de Janeiro: EdUERJ, 2005. vol. 1.

FREIRE, A.M.A. Inédito viável. In: STRECK, D.; REDIN, E.; ZITKOSKI, J. (Orgs.). Dicionário Paulo Freire. Belo Horizonte: Autêntica, 2008.

FREIRE, P. Pedagogia da esperança: um reencontro com a Pedagogia do Oprimido. São Paulo: Paz e Terra, 2006.

FREIRE, P. Pedagogia da indignação: cartas pedagógicas e outros escritos. São Paulo: Editora UNESP, 2000.

FREIRE, P. Pedagogia do Oprimido. Rio de Janeiro: Paz e Terra, 1987.

FREIRE, P. Medo e Ousadia: o cotidiano do professor. Rio de Janeiro: Paz e Terra, 1986.

FREIRE, P. Educação e mudança. Rio de Janeiro: Paz e Terra, 1983.

FREIRE, P. Ação cultural para a liberdade. 5ed. Rio de Janeiro: Paz e Terra, 1981.

FREIRE, P. Educação e mudança. Rio de Janeiro: Paz e Terra, 1979.

FREITAS, A.L.S. de. Pedagogia da conscientização: um legado de Paulo Freire à formação de professores. Porto Alegre: EDIPUCRS, 2004.

GHIGGI, G. A autoridade a serviço da liberdade: diálogos com Paulo Freire e professores em formação. Revista Perspectiva, Florianópolis, v. 19, n.2, p.469-492, jul./dez. 2001.

MORE, T. Utopia. Trad. Jefferson Luiz Camargo; Marcelo Brandão Cipolla. São Paulo: Martins Fontes, 1999. 
Enviado em Janeiro/2013 Aprovado em Novembro/2013 